\title{
Pharmacological Profile of the Novel Antiepileptic Drug Candidate Padsevonil: Interactions with Synaptic Vesicle 2 Proteins and the $\mathrm{GABA}_{\mathrm{A}}$ Receptor
}

\author{
Martyn Wood, Veronique Daniels, ${ }^{1}$ Laurent Provins, Christian Wolff, Rafal M. Kaminski, ${ }^{2}$ \\ and Michel Gillard
}

UCB Pharma, Neurosciences Therapeutic Area, Braine l'Alleud, Belgium

Received July 8, 2019; accepted October 10, 2019

\begin{abstract}
Padsevonil is an antiepileptic drug (AED) candidate synthesized in a medicinal chemistry program initiated to rationally design compounds with high affinity for synaptic vesicle 2 (SV2) proteins and low-to-moderate affinity for the benzodiazepine binding site on $\mathrm{GABA}_{\mathrm{A}}$ receptors. The pharmacological profile of padsevonil was characterized in binding and electrophysiological experiments. At recombinant SV2 proteins, padsevonil's affinity for SV2A was greater than that of levetiracetam and brivaracetam (pKi 8.5, 5.2, and 6.6, respectively). Unlike the latter AEDs, both selective SV2A ligands, padsevonil also displayed high affinity for the SV2B and SV2C isoforms (pKi 7.9 and 8.5, respectively). Padsevonil's interaction with SV2A differed from that of levetiracetam and brivaracetam; it exhibited slower binding kinetics: dissociation $t_{1 / 2} 30$ minutes from the human protein at $37^{\circ} \mathrm{C}$ compared with $<0.5$ minute for levetiracetam and brivaracetam. In addition, its binding was not potentiated by the allosteric modulator UCB1244283. At recombinant $\mathrm{GABA}_{\mathrm{A}}$ receptors, padsevonil displayed low to moderate affinity $\left(\mathrm{plC}_{50} \leq 6.1\right)$ for the benzodiazepine site, and in electrophysiological studies, its relative efficacy compared with zolpidem (full-agonist reference drug) was $40 \%$, indicating partial agonist properties. In
\end{abstract}

in vivo (mice) receptor occupancy studies, padsevonil exhibited SV2A occupancy at low $\mathrm{ED}_{50}(0.2 \mathrm{mg} / \mathrm{kg})$ and benzodiazepine site occupancy at higher doses ( $E D_{50} 36 \mathrm{mg} / \mathrm{kg}$ ), supporting in vitro results. Padsevonil's selectivity for its intended targets was confirmed in profiling studies, where it lacked significant effects on a wide variety of ion channels, receptors, transporters, and enzymes. Padsevonil is a first-in-class AED candidate with a unique target profile allowing for presynaptic and postsynaptic activity.

\section{SIGNIFICANCE STATEMENT}

Padsevonil is an antiepileptic drug candidate developed as a single molecular entity interacting with both presynaptic and postsynaptic targets. Results of in vitro and in vivo radioligand binding assays confirmed this target profile: padsevonil displayed nanomolar affinity for the three synaptic vesicle 2 protein isoforms (SV2A, B, and C) and micromolar affinity for the benzodiazepine binding site on $\mathrm{GABA}_{\mathrm{A}}$ receptors. Furthermore, padsevonil showed greater affinity for and slower binding kinetics at SV2A than the selective SV2A ligands, levetiracetam, and brivaracetam.

\section{Introduction}

Levetiracetam (LEV) was the first antiepileptic drug (AED) shown to exert its therapeutic activity by targeting elements of the synaptic release machinery, namely, through binding to the synaptic vesicle 2A (SV2A) protein (Lynch et al., 2004). SV2A and the other two protein isoforms-SV2B and SV2Care integral membrane glycoproteins that are present in secretory vesicles of neurons and endocrine cells (Bartholome et al., 2017). The precise function of the proteins remains elusive; however, given their presence in secretory vesicles, it

All studies described in this report were funded by UCB Pharma

${ }^{1}$ Current affiliation: Laboratory for Neurobiology and Gene Therapy, Department of Neurosciences KU Leuven, Leuven, Belgium.

${ }^{2}$ Current affiliation: Roche Innovation Center Basel, F. Hoffmann-La Roche Ltd, Basel, Switzerland.

https://doi.org/10.1124/jpet.119.261149. is most likely that they play a role in vesicle exocytosis, an observation substantiated by accumulating evidence (MendozaTorreblanca et al., 2013). SV2A knockout mice die in a matter of weeks; however, in vitro recordings of neurons from very young SV2A knockout mice reveal a reduction in the frequency and amplitude of spontaneous inhibitory postsynaptic currents, potentially indicating a negative effect on GABA release from presynaptic neurons (Crowder et al., 1999). Data from animals lacking both SV2A and SV2B suggest that the absence of these proteins leads to presynaptic $\mathrm{Ca}^{2+}$ accumulation during consecutive action potentials, causing abnormal increases in neurotransmitter release (Janz et al., 1999a). The overall effect is destabilization of synaptic circuits and aberrant neurotransmission (Crowder et al., 1999; Janz et al., 1999a). LEV reduces both inhibitory and excitatory postsynaptic currents in an activitydependent manner, with the largest effect seen with the highest stimulation frequency (Meehan et al., 2012). Both LEV and

ABBREVIATIONS: 5-HT, serotonin; AED, antiepileptic drug; BRV, brivaracetam; BZD, benzodiazepine; CB, cannabinoid; GABA ${ }_{A} R$, GABA ${ }_{A}$ receptor; HEK, human embryonic kidney cell line; IL, interleukin; LEV, levetiracetam; PSL, padsevonil; SV2, synaptic vesicle protein 2; TLR, toll-like receptor. 
brivaracetam (BRV), a more potent and selective SV2A ligand (Klitgaard et al., 2016), produce frequency-dependent slowing of vesicle exocytosis and recycling, and of synaptic transmission (Meehan et al., 2011, 2012; Yang et al., 2015).

The substantial evidence for the role of SV2A in the pathophysiology of epilepsy (Löscher et al., 2016; Ohno and Tokudome, 2017) and the clinical utility of SV2A ligands in the treatment of patients with epilepsy ensured that drug-discovery programs focusing on SV2 ligands continued. One strand of research involved investigating the feasibility of designing a molecule with both presynaptic and postsynaptic activity via interaction with SV2 proteins and the $\mathrm{GABA}_{\mathrm{A}}$ receptor $\left(\mathrm{GABA}_{\mathrm{A}} \mathrm{R}\right)$, respectively. The rationale for targeting these proteins was based on observations that LEV markedly potentiated the activity of AEDs acting via GABAergic transmission, notably benzodiazepines (BZDs), in several animal models resulting in an improved efficacy/safety ratio (Kaminski et al., 2009a). More recent studies have shown that SV2A dysfunction resulting from a missense mutation (L174Q) results in a selective reduction in GABAergic transmission, rendering animals carrying the mutation highly susceptible to seizures and markedly facilitating kindling (Tokudome et al., 2016a,b).

In the subsequent rational medicinal chemistry design program, the focus was to develop a single molecule that could target SV2 proteins with high affinity and postsynaptic GABA $_{A} R s$, specifically the BZD binding site, with lower affinity. Low-to-moderate affinity for this site, coupled with a partial agonist profile, could minimize the potential for the development of tolerance, a phenomenon known to occur with most BZDs (Vinkers and Olivier, 2012; Gravielle 2016). Lead optimization efforts led to the discovery of padsevonil (PSL), an imidazothiadiazole heterocycle coupled to a pyrrolidone moiety (Fig. 1). PSL constitutes a novel chemical class, as indicated by its International Nonproprietary Name, which was approved by the World Health Organization in 2017.

The objectives of the studies reported here are to characterize the interactions of PSL with its intended therapeutic targets and to determine its selectivity for these targets using an array of validated in vitro and in vivo techniques. The pharmacological profile of PSL in nonclinical models of seizures and epilepsy is reported in the accompanying article (Leclerq et al., 2019).

\section{Materials and Methods}

\section{Animals}

Experimental procedures involving animals were conducted in compliance with guidance from the local ethics committee for animal

Padsevonil

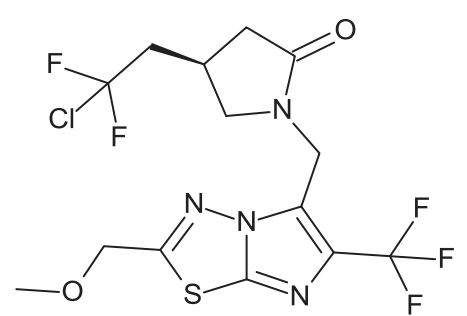

Fig. 1. Structure of padsevonil ((4R)-4-(2-chloro-2,2-difluoro-ethyl)-1[[2-(methoxymethyl)-6-(trifluoromethyl)imidazo[2,1-b][1,3,4] thiadiazol-5yl]methyl]pyrrolidin-2-one) compared with the prototypical SV2 ligand, levetiracetam (2S-(2-oxo-1-pyrrolidinyl)butanamide). experimentation according to Belgian law. All efforts were made to minimize animal suffering.

Naïve male specific pathogen-free NMRI mice (Crl:NMRI[Han]; 24-35 g) and male Sprague-Dawley rats (200-300 g) were obtained from Charles River Laboratories (Ecully, France). All animals were housed in a holding room under a 12-hour light/dark cycle with lights on at 06:00 hours. Temperature was maintained at $20-24^{\circ} \mathrm{C}$, relative humidity at $40 \%-70 \%$, and the rate of air replacement at least 15 times an hour. Animals had ad libitum access to standard dry pellet food and tap water.

\section{Radioligands, Drugs, and Chemicals}

The following compounds were synthesized at UCB (Braine l'Alleud, Belgium): PSL ((4R)-4-(2-chloro-2,2-difluoroethyl)-1-\{[2-(methoxymethyl)6-(trifluoromethyl)imidazo[2,1-b][1,3,4]thiadiazol-5-yl]methyl\}pyrrolidin2-one), LEV (2S-(2-oxo-1-pyrrolidinyl)butanamide), UCB30889 ((2S)-2-[4-(3-azidophenyl)-2-oxopyrrolidin-1-yl]butanamide), BRV (2S2-[(4R)-2-oxo-4-propylpyrrolidin-1-yl] butanamide), and UCB1244283 ((4-(3,5-dimethyphenyl)-N-(2-methoxyphenyl)-3-methylbutanamide). For in vitro studies, compounds were dissolved in DMSO, and for in vivo studies, PSL was dissolved in 0.1\%TWEEN 80 in $\mathrm{NaCl}(0.9 \%)$, and LEV and BRV in saline.

$\left[{ }^{3} \mathrm{H}\right] \mathrm{PSL}\left(2.55 \mathrm{Ci} \mathrm{mmol}^{-1}\right)$ and $\left.{ }^{3} \mathrm{H}\right] \mathrm{UCB} 30889\left(47 \mathrm{Ci} \mathrm{mmol}^{-1}\right)$ were custom-labeled by Aptuit (Greenwich, CT), and Amersham Biosciences (Amersham, UK), respectively. $\left[{ }^{3} \mathrm{H}\right]$ Flunitrazepam $\left(80-90 \mathrm{Ci} \mathrm{mmol}^{-1}\right.$ ) was purchased from GE Healthcare (Gent, Belgium). Human embryonic kidney cell line (HEK)* cells (Flp-In-293) and zeocin were purchased from Life Technologies (Merelbeke, Belgium), fibroblast-like cell line COS-7 cells from European Collection of Authenticated Cell Cultures, Sigma-Aldrich (Bornem, Belgium), complete protease inhibitor cocktail from Roche (Vilvoorde, Belgium) and DNAse (deoxyribonuclease I, type II from bovine pancreas) from Sigma-Aldrich. PBS, Dulbecco's modified Eagle's medium, L-glutamine, trypsin, and fetal bovine serum were purchased from Lonza (Verviers, Belgium). All other reagents were of analytical grade and obtained from conventional commercial sources.

Human cerebral cortex was obtained from Analytical Biologic Services Inc. (Wilmington, DE).

\section{Tissue and Membrane Preparations}

Preparation of Membrane Proteins from Rat and Human Cortex. Membrane proteins from rat cortex were prepared as described previously (Fuks et al., 2003). Briefly, after rats were sacrificed by decapitation, brains were removed rapidly and dissected on ice. All subsequent operations were performed at $4^{\circ} \mathrm{C}$. Brain tissue, either rat or human cerebral cortex, was homogenized (10\% w/v) in $20 \mathrm{mM}$ Tris$\mathrm{HCl}$ buffer ( $\mathrm{pH} 7.4$ ) containing $250 \mathrm{mM}$ sucrose (buffer A). Homogenates were spun at $30,000 \mathrm{~g}$ for 15 minutes, and the pellets were resuspended in the same buffer. After incubation at $37^{\circ} \mathrm{C}$ for 15 minutes, membranes were washed three times using the same centrifugation protocol. Final pellets were resuspended in buffer $\mathrm{A}$ at a protein concentration of $10-15 \mathrm{mg} \mathrm{ml}^{-1}$ and stored at $-140^{\circ} \mathrm{C}$ until further use.

Preparation of Membrane Proteins from HEK and COS-7 Cells. Human SV2A, B, and C were expressed in HEK cells and rat $\mathrm{GABA}_{\mathrm{A}} \mathrm{R}(\alpha 1 \beta 2 \gamma 2 ; \alpha 2 \beta 2 \gamma 2 ; \alpha 5 \beta 2 \gamma 2)$ in COS-7 cells. Cells were subcultured in Dulbecco's modified Eagle's medium containing $200 \mathrm{mM}$ L-glutamine and $100 \mu \mathrm{g} \mathrm{ml}^{-1}$ zeocin, supplemented with $10 \%$ fetal bovine serum, and grown in a humidified atmosphere of $5 \% \mathrm{CO}_{2}$ at $37^{\circ} \mathrm{C}$. Confluent cells were harvested by trypsinization and pelleted by centrifugation at $1500 \mathrm{~g}$ for 10 minutes at $4^{\circ} \mathrm{C}$. The pellet was washed with ice cold PBS using the same centrifugation protocol and homogenized in a buffer containing $15 \mathrm{mM}$ Tris-HCl, $1 \mathrm{mM}$ EGTA, $0.3 \mathrm{mM}$ EDTA, and $2 \mathrm{mM} \mathrm{MgCl}_{2}(\mathrm{pH}$ 7.5) supplemented with complete protease inhibitor cocktail. The homogenate was freeze-thawed twice and equilibrated at $25^{\circ} \mathrm{C}$ followed by a 10 -minute DNAse $\left(10 \mathrm{U} \mathrm{ml}^{-1}\right)$ treatment. The solution was centrifuged for 25 minutes at $40,000 \mathrm{~g}$ and $4^{\circ} \mathrm{C}$. Finally, the pellet was resuspended in buffer $\mathrm{A}$ at a protein concentration of $5-10 \mathrm{mg} \mathrm{ml}^{-1}$ and stored at $-140^{\circ} \mathrm{C}$ until further use. 


\section{Radioligand Binding Experiments}

Experiments were performed as previously described (Fuks et al., 2003). For all assays, membrane proteins ( $100 \mu \mathrm{g}$ per assay for cortical membrane proteins, 70-125 $\mu \mathrm{g}$ for SV2A, 2-5 $\mu \mathrm{g}$ for SV2B, 40-60 $\mu \mathrm{g}$ for SV2C, and 75-125 $\mu \mathrm{g}$ for rat $\mathrm{GABA}_{\mathrm{A}} \mathrm{R}$ subtypes) were incubated for 120 minutes at $4^{\circ} \mathrm{C}$ or $60-150$ minutes at $37^{\circ} \mathrm{C}$ in 0.5 or $2 \mathrm{ml}$ of Tris$\mathrm{HCl}$ buffer (50 mM, pH 7.4) containing $2 \mathrm{mM} \mathrm{MgCl}_{2}$. All glass fiber filters (from Brandel Inc., Gaithersburg, MD) used in the experiments were presoaked in $0.1 \%$ polyethyleneimine.

Competition Binding Experiments. Increasing concentrations of unlabeled competing drugs were added in the presence of 0.9 or $9 \mathrm{nM}\left[{ }^{3} \mathrm{H}\right] \mathrm{PSL}, 1$ or $4 \mathrm{nM}\left[{ }^{3} \mathrm{H}\right] \mathrm{UCB} 30889$ or $2 \mathrm{nM}\left[{ }^{3} \mathrm{H}\right]$ flunitrazepam. At the end of the incubation period, membrane-bound radioligand was recovered by rapid filtration through GF/B filters. Plates were washed rapidly three times with $0.3 \mathrm{ml}$ of ice-cold Tris buffer; the total washing procedure did not exceed 10 seconds.

Kinetic Experiments. Specific $\left[{ }^{3} \mathrm{H}\right] \mathrm{PSL}$ binding in association experiments was measured at the indicated times after addition of membrane proteins at $37^{\circ} \mathrm{C}$. Dissociation was induced by the addition of $10 \mu \mathrm{M}$ of unlabeled PSL to the association reaction mixture. Samples were filtered on GF/C filters and washed with $5 \mathrm{ml}$ of ice-cold Tris buffer. Total filtration time per sample did not exceed 2 seconds.

Saturation Binding Experiments. Membrane proteins were incubated with $\left[{ }^{3} \mathrm{H}\right] \mathrm{PSL}$ at concentrations ranging from 0.05 to $22 \mathrm{nM}$, and samples were filtered using GF/B filters. Nonspecific binding was defined as residual binding observed in the presence of $10 \mu \mathrm{M}$ unlabeled PSL for $\left[{ }^{3} \mathrm{H}\right] \mathrm{PSL}, 1 \mathrm{mM}$ LEV for $\left[{ }^{3} \mathrm{H}\right] \mathrm{UCB} 30889$, or $10 \mu \mathrm{M}$ diazepam for $\left[{ }^{3} \mathrm{H}\right]$ flunitrazepam. Radioactivity was determined by liquid scintillation.

The effect of UCB1244283, a positive allosteric modulator of SV2A, on PSL binding to SV2A was also evaluated. Studies were performed at $4^{\circ} \mathrm{C}$ according to the protocol described by Wood and Gillard (2017).

In Vivo Receptor Occupancy. The protocol developed by $\mathrm{Li}$ et al. (2006) was followed using NMRI mice instead of rats. Animals received vehicle (TWEEN/saline) or PSL (10 ml/kg body weight), administered intraperitoneally, followed 27 minutes later by tail-vein injections $(2 \mu \mathrm{l} / \mathrm{g})$ of either $\left[{ }^{3} \mathrm{H}\right] \mathrm{UCB} 30889(2 \mu \mathrm{Ci})$ or $\left[{ }^{3} \mathrm{H}\right]$ flunitrazepam $(1 \mu \mathrm{Ci})$. Necks of mice were dislocated 3 minutes after injection, and whole brains were rapidly removed, weighed, and homogenized in 10 volumes of ice-cold Tris buffer. The homogenate $(300 \mu \mathrm{l})$ was filtered over GF/C filters and washed three times with $2 \mathrm{ml}$ of ice-cold Tris buffer. Retained radioactivity was counted by liquid scintillation. Studies consisted of eight treatment groups (six PSL doses, one vehicle, one UCB30889/flunitrazepam), with six mice per group.

\section{Selectivity Studies}

Selectivity of PSL for its therapeutic targets was determined using radioligand binding, receptor activation, and electrophysiological studies.

Radioligand binding studies were performed at CEREP (le Bois l'Eveque, France) and at UCB (Braine l'Alleud, Belgium) according to standard protocols. PSL was evaluated at $10 \mu \mathrm{M}$ against a panel of various molecular targets, including ligand-gated and G-protein-coupled receptors, ion channels, transporters, and enzymes. Receptors included acetylcholine nicotinic (neuronal bungarotoxin-insensitive), acetylcholine muscarinic (M1, M2, and M3), adenosine (A1 and A2A), epinephrine/ norepinephrine ( $\alpha 1 \mathrm{~A}, \alpha 2 \mathrm{~A}, \beta 1$, and $\beta 2$ ), androgen, cannabinoid (CB1 and CB2), cholecystokinin, dopamine (D1, D2, D3, and D4), endothelin A, GABA $\left(\mathrm{GABA}_{\mathrm{A}}\right.$ and $\left.\mathrm{GABA}_{\mathrm{B}}\right)$, glycine, glucocorticoid, glutamate (AMPA, kainite, and NMDA), neurokinin (NK1, NK2, and NK3), serotonin (5HT1A, 5-HT1B, 5-HT1D, 5-HT2A, 5HT2B, 5-HT2C, 5-HT3, 5-HT4, 5HT5A, 5-HT6, and 5-HT7), transforming growth factor $\beta 1$, opioid $(\delta, \kappa$, and $\mu$ ), histamine (H1, H3, and H4), sigma 1 and vasopressin (V1a) receptors. Ion channels included L- and $\mathrm{N}$-type voltage-gated $\mathrm{Ca}^{2+}$ channels $\left(\mathrm{Ca}_{\mathrm{V}}\right)$, voltage-gated $\mathrm{Na}^{+}$channels, and $\mathrm{Ca}^{2+}$-activated, ATP-sensitive and voltage-gated $\mathrm{K}^{+}$channels. Other targets were transporters, including adenosine, norepinephrine, dopamine, GABA, and 5-HT transporters, as well the enzymes phospholipase
A2, cyclooxygenase 1 and 2, constitutive nitric oxide synthase, catechol-O-methyl transferase, GABA transaminase, and tyrosine hydroxylase.

Receptor activation studies were conducted at Eurofins Panlabs (St. Charles, MO) using standard protocols. The ability of PSL at concentrations of $1,3,10$, and $30 \mu \mathrm{M}$ to activate toll-like receptors (TLR 2 and 4) on cultured human peripheral blood mononuclear cells was evaluated by measuring concentrations of specific cytokines in the culture supernatant after stimulation. Cytokines tested included interleukin (IL)-1 $\beta$, IL-6, IL-10, IL-12p40, and tumor necrosis factor $\alpha$.

The effects of $10 \mu \mathrm{M}$ PSL on selected ion channels was determined at B'SYS (Witterswil, Switzerland) using standard protocols. These included endogenous $\mathrm{Na}^{+}$channels expressed in N1E-115 cells; Cav2.1, voltage-gated $\mathrm{K}^{+} \mathrm{K}_{\mathrm{V}} 7.2 / 7.3$ channels, AMPA receptors (GRIA 1) and kainate receptors (GluK2/GluK5) expressed in Chinese hamster ovary cells; Cav3.2 channels and NMDA (NR1/NR2A, NR1/NR2B) receptors expressed in HEK cells.

\section{Functional Electrophysiological Studies}

Electrophysiological recordings from $\mathrm{GABA}_{\mathrm{A}}$ channels were performed as described previously (Ghisdal et al., 2014). Briefly, $\mathrm{Cl}^{-}$ currents were recorded from a Chinese hamster ovary-K1 cell line expressing the recombinant human $\alpha 1 \beta 2 \gamma 2$ GABA $_{\mathrm{A}} \mathrm{R}$ subtype. Patchclamp recordings were performed on a PatchXpress system (Molecular Devices, Sunnyvale, CA). During all procedures, the holding potential was set to $-60 \mathrm{mV}$. Whole-cell compensation was automatically set before each experiment. Current traces were recorded by patch-clamp amplifier (Multiclamp 700A computer-controlled patch-clamp dual headstage amplifier; Axon Instruments) at a sampling rate of $2 \mathrm{kHz}$. Recordings were performed at room temperature $\left(\sim 25^{\circ} \mathrm{C}\right)$.

\section{Data Analysis}

In radioligand binding studies, data were analyzed by computerized nonlinear curve-fitting methods (Graphpad Prism 5 software, San Diego, CA), according to equations describing several binding models (Molinoff et al., 1981). IC $_{50}$ values were corrected to $K_{i}$ by applying the Cheng and Prusoff equation (Cheng and Prusoff, 1973).

In electrophysiological studies, data were analyzed using DataXpress 2 software (version 2.0.4.2; Molecular Devices). The potentiation of $\mathrm{GABA}_{\mathrm{A}}$-evoked $\mathrm{Cl}^{-}$currents in the presence of drug was determined and compared with the maximum potentiation in the presence of $1 \mu \mathrm{M}$ zolpidem.

\section{Results}

\section{Affinity for SV2A and the BZD Site}

To determine the affinity of PSL for SV2A, the radioligand $\left[{ }^{3} \mathrm{H}\right] \mathrm{UCB} 30889$ was used in competition experiments in human and rat cortexes. This compound is an LEV analog with 20-fold greater affinity for SV2A than LEV, which makes it a suitable radioligand for labeling SV2A (Gillard et al., 2003, 2006). $\left[{ }^{3} \mathrm{H}\right]$ Flunitrazepam, a BZD with full agonist properties, was used for determining the affinity of PSL for the BZD site. PSL exhibited nanomolar affinity for SV2A labeled with $\left[{ }^{3} \mathrm{H}\right]$ UCB30889 and micromolar affinity for the BZD site labeled with $\left[{ }^{3} \mathrm{H}\right]$ flunitrazepam (Table 1). Further studies on human recombinant $\mathrm{GABA}_{\mathrm{A}} \mathrm{R}$ subtypes $(\alpha 1 \beta 2 \gamma 2, \alpha 2 \beta 2 \gamma 2$, and $\alpha 5 \beta 2 \gamma 2)$ yielded $\mathrm{pIC}_{50}$ values of $6.1 \pm 0.1(n=4),<5(n=$ $3)$, and $6.0 \pm 0.1(n=3)$, respectively, at $4^{\circ} \mathrm{C}$.

\section{In Vivo SV2A and BZD Site Occupancy}

The binding profile of PSL to SV2A and the BZD site was also characterized in vivo, where results were similar to those obtained using cortical preparations: SV2A occupancy was 
observed at low doses and BZD site occupancy at higher doses, indicating a greater PSL affinity for SV2A than the BZD site. In the dose-range administered intraperitoneally in mice, PSL $\mathrm{ED}_{50}$ for SV2A occupancy was $0.4 \mu \mathrm{mol} / \mathrm{kg}\left(0.2 \mathrm{mg} / \mathrm{kg} ; \mathrm{pED}_{50}\right.$ $6.4 \mathrm{~mol} / \mathrm{kg}$ ), whereas that of BZD site occupancy was markedly higher at $72 \mu \mathrm{mol} / \mathrm{kg}\left(36 \mathrm{mg} / \mathrm{kg} ; \mathrm{pED}_{50} 4.14 \mathrm{~mol} / \mathrm{kg}\right.$ ) (Fig. 2).

\section{Binding Characteristics at SV2 Isoforms}

Detailed characterization of PSL binding to the three SV2 isoforms was performed using $\left[{ }^{3} \mathrm{H}\right] \mathrm{PSL}$, the tritium-radiolabeled compound.

Kinetic Experiments. Binding kinetics of $\left[{ }^{3} \mathrm{H}\right] \mathrm{PSL}$ were determined on human recombinant SV2 isoforms expressed in HEK cells and in human and rat cortex at $37^{\circ} \mathrm{C}$ (Fig. 3; Table 2). $\left[{ }^{3} \mathrm{H}\right] \mathrm{PSL}$ association kinetics were monophasic at all protein sources. Dissociation kinetics were also monophasic for the recombinant SV2 isoforms but more complex in human and rat cortex, although no clear separation of the phases was evident.

Saturation Binding Experiments. Saturation binding curves of $\left[{ }^{3} \mathrm{H}\right] \mathrm{PSL}$ on human recombinant SV2A/B/C and on human and rat cortex proteins were compatible with the labeling of a homogeneous population of binding sites at $37^{\circ} \mathrm{C}$ (Fig. 4). Corresponding affinities and $B_{\max }$ values are given in Table 3. The affinity of $\left[{ }^{3} \mathrm{H}\right] \mathrm{PSL}$ was similar for all protein sources, and the $K_{\mathrm{d}}$ value obtained for recombinant human SV2A corresponded with the $\mathrm{K}_{i}$ obtained for the unlabeled compound using $\left[{ }^{3} \mathrm{H}\right] \mathrm{UCB} 30889$ (Table 1).

UCB1244283 is a positive allosteric modulator of SV2A that increases the binding of BRV and LEV to the protein (Daniels et al., 2013). Use of the modulator (at $30 \mu \mathrm{M}$ and at $4^{\circ} \mathrm{C}$ ) had no effect on the $B_{\max }$ for $\left[{ }^{3} \mathrm{H}\right] \mathrm{PSL}$ binding to the human SV2A protein in HEK membranes, but it reduced the affinity from 2.3 $\pm 0.2 \mathrm{nM}(n=3)$ to $3.90 \pm 0.5 \mathrm{nM}(P<0.05$, Student's $t$ test $)$.

Competition Experiments. Competition experiments were performed on all human recombinant SV2 isoforms expressed in HEK cells and on human and rat cortex proteins using several SV2A ligands, as well as diazepam (Fig. 5). These experiments were performed with $0.9 \mathrm{nM}\left[{ }^{3} \mathrm{H}\right] \mathrm{PSL}$. Data were analyzed using sigmoidal dose-response fits with variable slope, and the resulting $\mathrm{pIC}_{50}$ values were transformed into $\mathrm{pK}_{\mathrm{i}}$ values (Table 4). The affinity of the selective SV2A ligands-LEV, UCB30889, and BRV-was very low for both SV2B and SV2C labeled with $\left[{ }^{3} \mathrm{H}\right] \mathrm{PSL}$, resulting in incomplete competition curves at the concentration range used. This finding is in line with previous reports, demonstrating the selectivity of LEV and BRV for SV2A (Noyer et al., 1995; Gillard et al., 2011). Competition with PSL led to a complete displacement of $\left[{ }^{3} \mathrm{H}\right] \mathrm{PSL}$ binding on all protein sources. For all human recombinant SV2 isoforms, the Hill

\section{TABLE 1}

Affinity of padsevonil for sites labeled with $\left[{ }^{3} \mathrm{H}\right] \mathrm{UCB} 30889$ (SV2A) and $\left[{ }^{3} \mathrm{H}\right]$ flunitrazepam (benzodiazepine site of the $\mathrm{GABA}_{\mathrm{A}}$ receptor) in human and rat cortex at $37^{\circ} \mathrm{C}$. Results are the mean \pm S.D. of at least three independent experiments. Data from competition curves were analyzed by nonlinear regression using a sigmoidal dose-response model with variable slope.

\begin{tabular}{lcc}
\hline Radioligand & Tissue & $\mathrm{pIC}_{50}$ \\
\hline$\left[{ }^{3} \mathrm{H}\right]$ UCB30889 & Rat cortex & $8.43 \pm 0.38$ \\
& Human cortex & $8.97 \pm 0.15$ \\
{$\left[{ }^{3} \mathrm{H}\right]$ flunitrazepam } & Rat cortex & $5.50 \pm 0.17$ \\
& Human cortex & $5.80 \pm 0.17$ \\
\hline
\end{tabular}

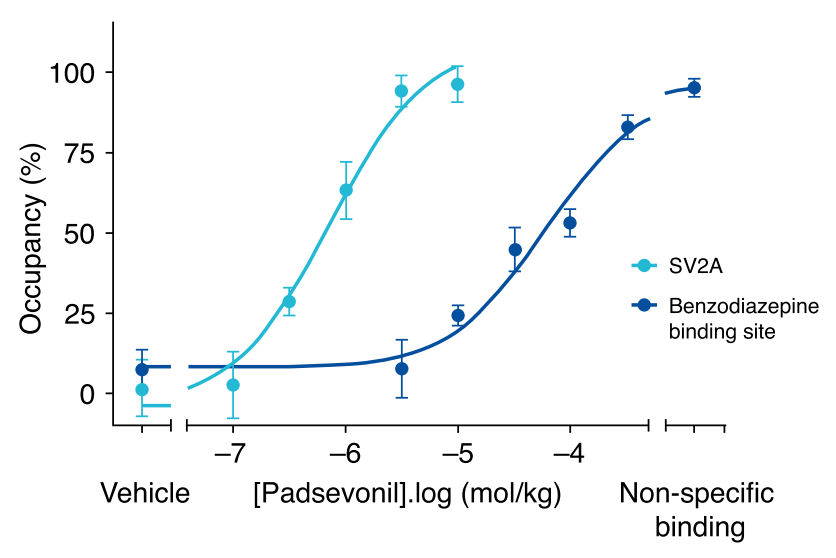

Fig. 2. In vivo occupancy of synaptic vesicle $2 \mathrm{~A}$ (SV2A) protein and the benzodiazepine binding site of $\mathrm{GABA}_{\mathrm{A}}$ receptors by padsevonil in mouse cortex 30 minutes after intraperitoneal administration.

slopes of the curve fits were not different from unity, and the obtained $K_{\mathrm{i}}$ values for PSL agreed with the $K_{\mathrm{d}}$ values of the radiolabeled compound.

In human and rat cortex, the competition curves of LEV, BRV, and UCB30889 fitted on the data using a sigmoidal doseresponse curve with variable slope were shallower than those for PSL. The corresponding Hill coefficients ranged from -0.8 to -0.7 and reached significant difference from unity for LEV in both human and rat cortex $(P<0.01)$ and for UCB30889 and BRV in rat cortex $(P<0.01)$ (Table 4). The pronounced shallow profile of these competition curves allowed analysis of data with a model describing the binding to two independent populations of binding sites. At a radioligand concentration of $0.9 \mathrm{nM}$, the result fit with $85 \%$ of the binding sites having an affinity similar to that on recombinant human SV2A, and the remaining sites displaying an affinity in the low millimolar range. The latter proportion of binding sites most likely represents the SV2B component, given the very low presence of SV2C in the cortex.

\section{Effects in Selectivity Studies}

Selectivity of PSL for its therapeutic targets was determined using radioligand binding, receptor activation and electrophysiological studies.

In radioligand studies, PSL at $10 \mu \mathrm{M}$ lacked significant effects ( $>50 \%)$ on a wide variety of molecular targets, including ligand-gated and G-protein-coupled receptors, ion channels, transporters, and enzymes. The only significant effect was at the BZD binding site of the $\mathrm{GABA}_{\mathrm{A}} \mathrm{R}$ (87\% inhibition), confirming the profile described already here. Approximately $50 \%$ inhibition of binding to the human neurokinin NK2 receptor was also observed and subsequently confirmed in a concentrationresponse study with a $\mathrm{pIC}_{50}$ of 5 .

In receptor activation assays, PSL at concentrations up to $30 \mu \mathrm{M}$ failed to elicit release of any of the tested cytokines from human peripheral blood mononuclear cells, indicating a lack of activity on TLR 2 and 4 . In electrophysiological studies, PSL at $10 \mu \mathrm{M}$ had no significant effect on any of the classic AED targets such as voltage-gated ion channels or glutamatergic receptors.

\section{Activity at Recombinant $\mathrm{GABA}_{\mathrm{A}}$ Receptors}

In the recombinant human $\alpha 1 \beta 2 \gamma 2 \mathrm{GABA}_{\mathrm{A}} \mathrm{R}$ subtype, application of GABA resulted in activation of $\mathrm{Cl}^{-}$currents 


\section{Human recombinant SV2A}
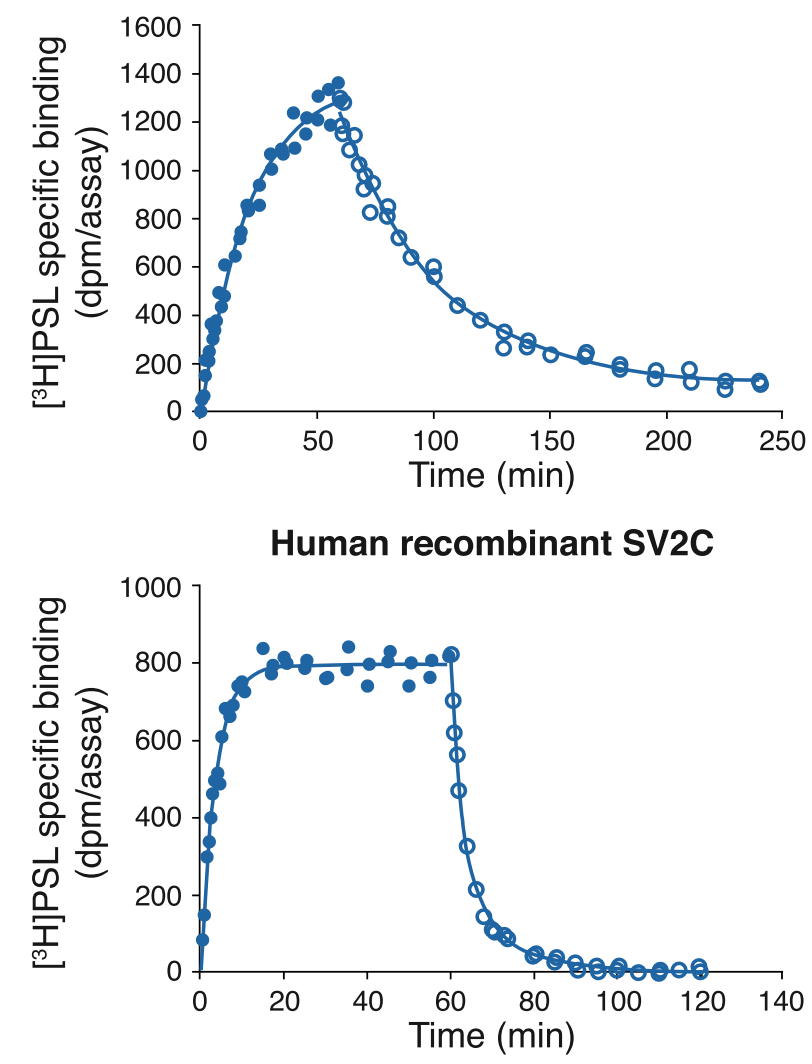

Rat cortex

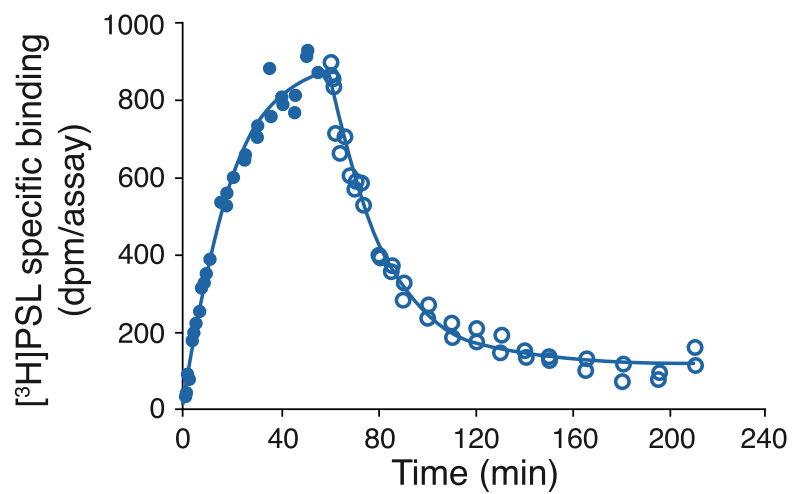

Human recombinant SV2B

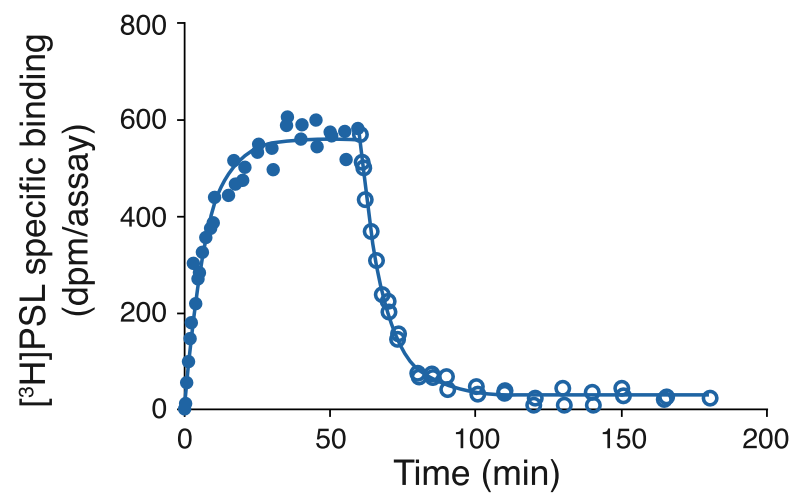

Human cortex

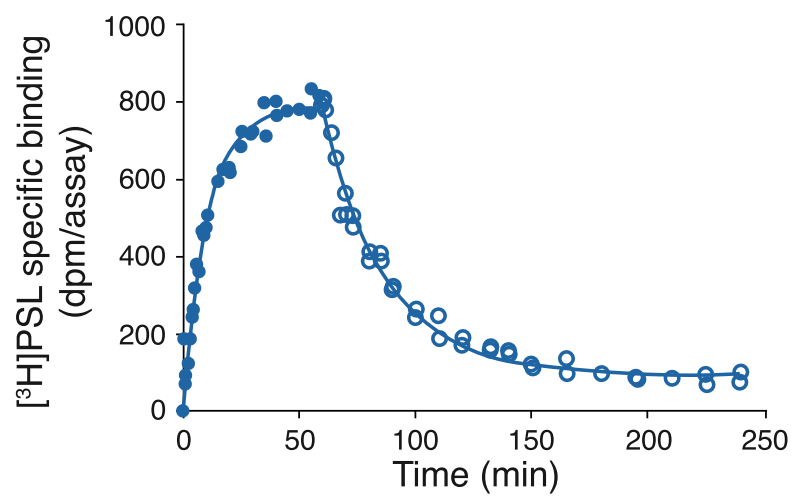

Fig. 3. Binding kinetics of $\left[{ }^{3} \mathrm{H}\right]$ padsevonil at $37^{\circ} \mathrm{C}$ on human recombinant $\mathrm{SV} 2 \mathrm{~A} / \mathrm{B} / \mathrm{C}$ expressed in HEK cells and in human and rat cortex. Filled circles represent association, and open circles represent dissociation binding kinetics. The curves are the best fit of data obtained using equations describing binding to a single site. Data represent specific binding obtained by subtracting nonspecific binding (residual binding in the presence of $10 \mu \mathrm{M}$ of unlabeled padsevonil) from total binding and have been obtained from at least three independent experiments.

with an $\mathrm{EC}_{50}$ of $15 \mu \mathrm{M}$ (data not shown). To evaluate the effects of drugs on these GABA-evoked $\mathrm{Cl}^{-}$currents, an agonist concentration corresponding to its $\mathrm{EC}_{20}(5 \mu \mathrm{M})$ was selected.

$\mathrm{PSL}$, in a concentration range of $1 \mathrm{nM}-30 \mu \mathrm{M}$, when added alone for 5 minutes during preincubation, did not significantly change basal $\mathrm{Cl}^{-}$currents compared with control (DMSO $0.5 \%$, data not shown) but potentiated $\mathrm{Cl}^{-}$currents evoked by $5 \mu \mathrm{M}$ GABA. Potentiation of GABA-induced $\mathrm{Cl}^{-}$currents was dose-dependent with an $\mathrm{EC}_{50}$ of $137 \mathrm{nM}$ and a maximal effect reaching $167 \%$ (Fig. 6).

The relative efficacy of PSL in potentiating $\mathrm{GABA}_{\mathrm{A}} \mathrm{R} \mathrm{Cl}^{-}$ currents was compared with that of zolpidem, a reference drug included in each experiment. Zolpidem is a full agonist at the BZD site and potentiates $\mathrm{GABA}\left[\mathrm{EC}_{20}\right]$ with a maximal efficacy at $1 \mu \mathrm{M}$. The relative efficacy of PSL at $10 \mu \mathrm{M}$ was $44 \% \pm 16 \%$ compared with the maximal response to zolpidem defined as $100 \%$.

\section{Discussion}

PSL was developed in a rational drug-discovery program initiated to develop a molecule with a novel mode of action aimed at the treatment of patients with drug-resistant epilepsy. Results of experiments described here confirm that PSL is a high-affinity pan-SV2 ligand, and it acts as a lowaffinity partial agonist at the BZD site of $\mathrm{GABA}_{\mathrm{A}} \mathrm{Rs}$. Profiling studies also confirmed the lack of effect on typical AED targets, such as ion channels and glutamate receptors, as well 
TABLE 2

Kinetic constants of $\left[{ }^{3} \mathrm{H}\right]$ padsevonil binding on human recombinant synaptic vesicle protein $2(\mathrm{SV} 2) \mathrm{A} / \mathrm{B} / \mathrm{C}$ and in human and rat cortex at $37^{\circ} \mathrm{C}$. Kinetic constants were calculated by nonlinear regression analysis of association and dissociation curves of $\left[{ }^{3} \mathrm{H}\right] \mathrm{PSL}$ as depicted in Fig. 3 using a model describing the interaction of a ligand with a single site showing the calculated affinity constant $\left(K_{\mathrm{D}}\right)$. Data represent mean \pm S.D.

\begin{tabular}{|c|c|c|c|c|c|}
\hline & SV2A & SV2B & SV2C & Rat Cortex & Human Cortex \\
\hline Association & $n=4$ & $n=3$ & $n=3$ & $n=3$ & $n=3$ \\
\hline$K_{\mathrm{on}}\left(\mathrm{nM}^{-1} \cdot \min ^{-1}\right)$ & $0.02 \pm 0.01$ & $0.02 \pm 0.03$ & $0.04 \pm 0.03$ & $0.01 \pm 0.004$ & $0.06 \pm 0.01$ \\
\hline$t_{1 / 2}(\min )$ & $13.9 \pm 2.1$ & $4.7 \pm 0.8$ & $2.6 \pm 0.2$ & $12.4 \pm 0.8$ & $7.9 \pm 0.7$ \\
\hline$k_{\text {off }}\left(\min ^{-1}\right)$ & $0.02 \pm 0.01$ & $0.13 \pm 0.02$ & $0.20 \pm 0.02$ & $0.04 \pm 0.01$ & $0.04 \pm 0.01$ \\
\hline$t_{1 / 2}(\min )$ & $29.0 \pm 5.8$ & $5.4 \pm 0.9$ & $3.6 \pm 0.4$ & $16.0 \pm 0.4$ & $17.3 \pm 2.8$ \\
\hline$K_{\mathrm{D}}(\mathrm{nM})$ & 1 & 7 & 7 & 4 & 1 \\
\hline
\end{tabular}

$k_{o f f}$ is the dissociation kinetic constant; $k_{o n}$ is the association kinetic constant; and $t_{1 / 2}$ is the association or dissociation half-time.

as a variety of other central nervous system targets, including ligand-gated and G-protein-coupled receptors, transporters and enzymes.

PSL is the first ligand that interacts with all three SV2 isoforms. In saturation and competition studies, $\left[{ }^{3} \mathrm{H}\right] \mathrm{PSL}$ displayed nanomolar affinity for SV2A, SV2B, and SV2C. This finding was in contrast to LEV and BRV, both displaying marked selectivity for SV2A and interacting with SV2B and SV2C only at concentrations 100-fold higher than that at which they interacted with SV2A. This finding was also consistent with the lack of binding of a LEV derivative and of $\left[{ }^{3} \mathrm{H}\right] \mathrm{BRV}$ in mouse brain tissue lacking SV2A (Lynch et al., 2004; Gillard et al., 2011). The high affinity of $\left[{ }^{3} \mathrm{H}\right] \mathrm{PSL}$ for all isoforms was also reflected in kinetic data. $\left[{ }^{3} \mathrm{H}\right] \mathrm{PSL}$ dissociation kinetics were monophasic at human recombinant SV2 isoforms but more complex in human and rat cortex, most likely owing to the labeling of a relatively low fraction of SV2B and SV2A at $0.9 \mathrm{nM}\left[{ }^{3} \mathrm{H}\right] \mathrm{PSL}$. At this concentration, relatively more SV2A binding sites are labeled since $\left[{ }^{3} \mathrm{H}\right] \mathrm{PSL}$ has a 4-fold higher affinity for SV2A $\left(\mathrm{K}_{\mathrm{d}} 1.5 \mathrm{nM}\right)$ than for SV2B $\left(\mathrm{K}_{\mathrm{d}}\right.$ $6.3 \mathrm{nM}$ ). Labeling of only a small proportion of SV2B in both human and rat cortex is supported by results of competition experiments; SV2C labeling was not anticipated given its restricted expression in the cortex (see the following). Results with LEV and BRV demonstrated labeling of approximately $85 \%$ of the binding sites with affinities similar to that at human recombinant SV2A. Finally, both SV2A and SV2B labeling in the cortex is supported by the observation that the
$B_{\max }$ values for [ $\left.{ }^{3} \mathrm{H}\right] \mathrm{PSL}$ were approximately twice as high as those observed for SV2A-selective ligands (Gillard et al., 2003, 2011). Results do not allow an accurate prediction of the SV2A/ $B$ ratio in the cortex because differences in the labeling of both isoforms in native versus recombinant expression systems cannot be excluded. Overall, results are consistent with the interaction of PSL with all three SV2 isoforms and suggest that it may be a useful ligand in further characterization of these proteins.

The roles of SV2B and SV2C in the pathophysiology of epilepsy remain unknown. Few reports have addressed the role of SV2B since its distribution in the mammalian brain partly overlaps with that of SV2A (Bajjalieh et al., 1993, 1994). $\mathrm{SV}_{2 \mathrm{~B}}{ }^{-1-}$ mice do not show phenotypic abnormalities, and electrophysiological studies on cultured neurons from these mice do not reveal any obvious effects on neurotransmission (Janz et al., 1999a; Chang and Südhof, 2009; Venkatesan et al., 2012). In a recent study, SV2C expression was strongest in the basal ganglia and more restricted in the cortex of rodent, rhesus macaque, and human brain (Dunn et al., 2019), consistent with results from previous rodent studies (Janz and Südhof, 1999b; Dardou et al., 2011). In the human brain, SV2C was highly colocalized with the GABA transporter in the striatum, substantia nigra, and ventral tegmental area (Dunn et al., 2019). SV2C expression was weak or absent in the hippocampus of autopsy controls, but it increased in biopsies from patients with temporal lobe epilepsy owing to mesial temporal sclerosis; in contrast, SV2A and SV2B expression
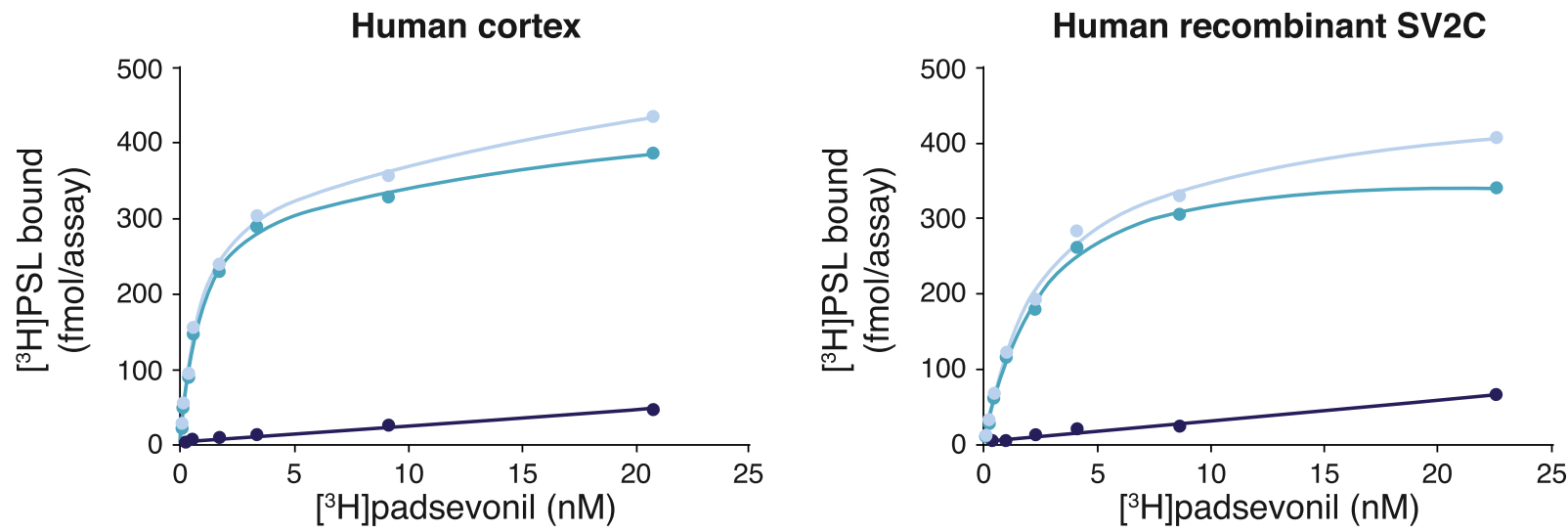

- Specific binding - Total binding

- Non-specific binding

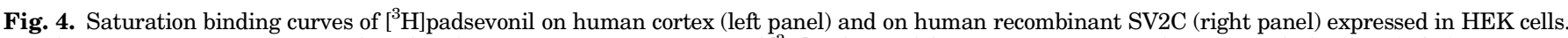

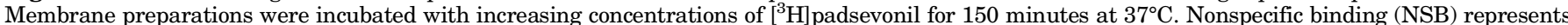

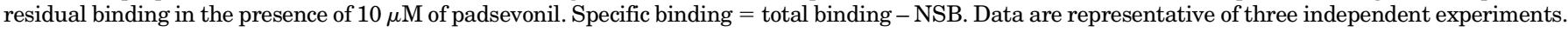


TABLE 3

$K_{\mathrm{d}}$ and $B_{\max }$ values of $\left[{ }^{3} \mathrm{H}\right]$ padsevonil on human recombinant synaptic vesicle protein $2(\mathrm{SV} 2) \mathrm{A} / \mathrm{B} / \mathrm{C}$ and on human and rat cortex at $37^{\circ} \mathrm{C}$. Data represent mean \pm S.D. $(n=3)$ and were obtained from the analysis of saturation curves as presented in Fig. 4 using a nonlinear regression model describing binding to a single site.

\begin{tabular}{lccccc}
\hline & SV2A & SV2B & SV2C & Rat Cortex & Human Cortex \\
\hline$K_{\mathrm{d}}(\mathrm{nM})$ & $1.53 \pm 0.15$ & $6.34 \pm 1.67$ & $2.40 \pm 0.16$ & $2.73 \pm 1.04$ & $2.11 \pm 0.84$ \\
$B_{\max }(\mathrm{pmol} / \mathrm{mg})$ & $109.9 \pm 3.2$ & $52.8 \pm 7.8$ & $23.8 \pm 4.6$ & $27.3 \pm 9.2$ & $9.3 \pm 1.6$ \\
\hline
\end{tabular}

levels were decreased (Crèvecoeur et al., 2014). Since PSL has high affinity for all three SV2 isoforms, it could be postulated that binding to SV2B/C, in addition to SV2A, may contribute to broader, more sustained antiseizure effects.
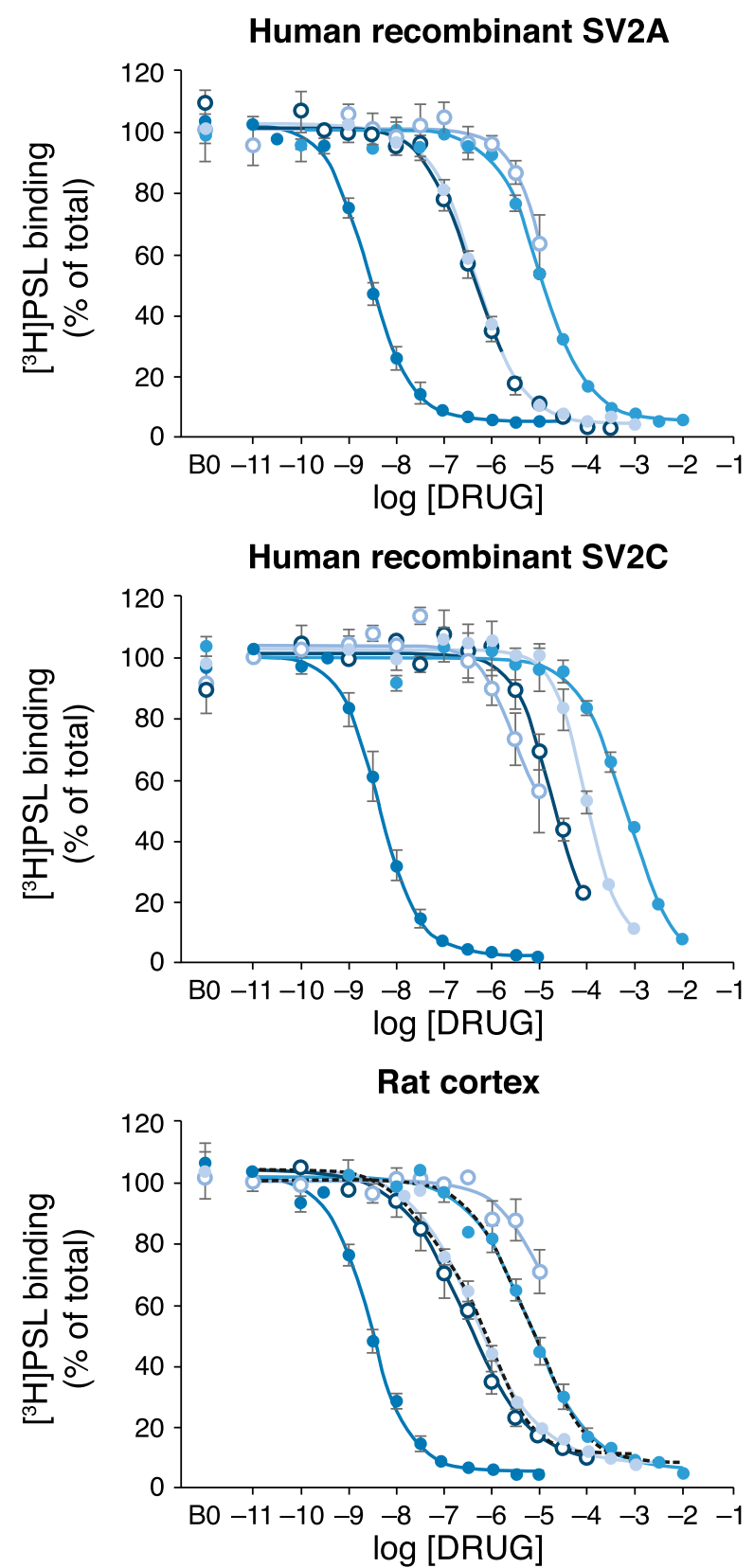

PSL differs from SV2A-selective ligands not only in its affinity for SV2B and SV2C, but also in its interaction with SV2A, as suggested by the slow kinetics of $\left[{ }^{3} \mathrm{H}\right] \mathrm{PSL}$ and the effect of the modulator, UCB1244283. BRV and LEV have
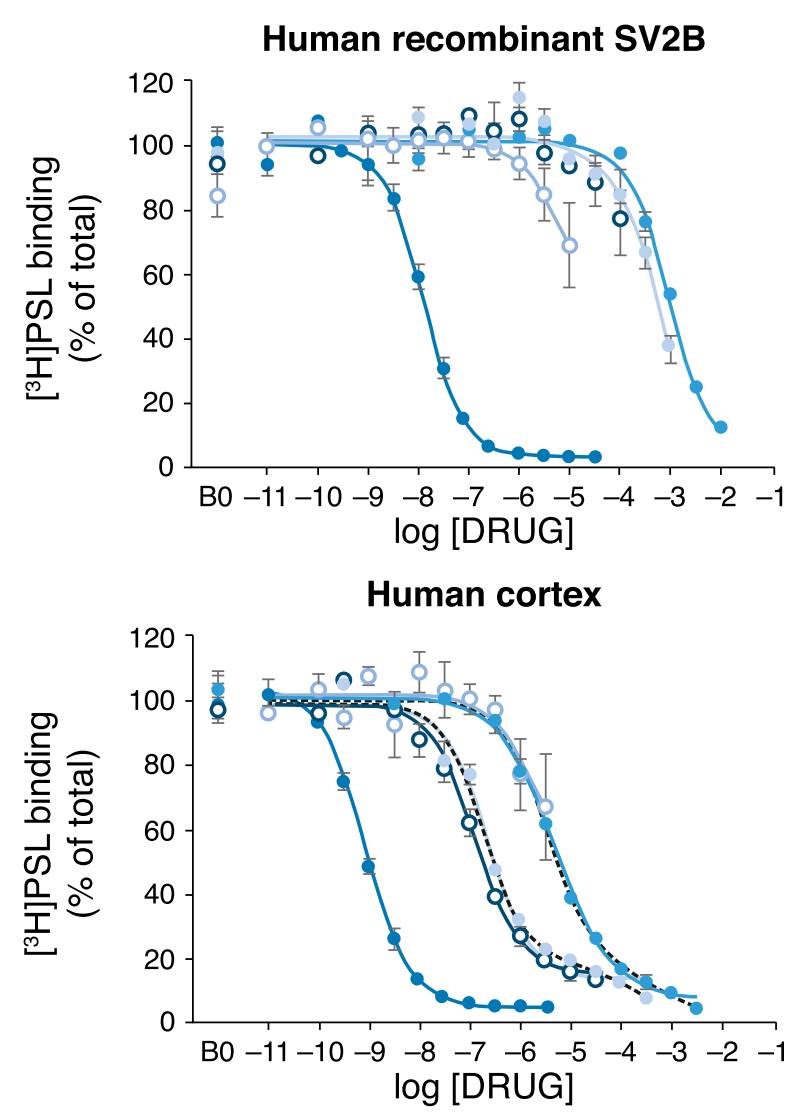

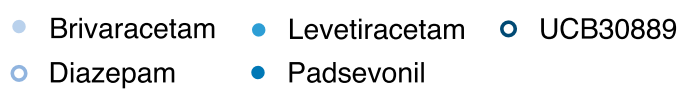

Fig. 5. Affinity of compounds for sites labeled with $\left[{ }^{3} \mathrm{H}\right]$ padsevonil in human recombinant SV2A/B/C proteins and on rat and human cortex. A concentration range of the compounds was incubated with $0.9 \mathrm{nM}\left[{ }^{3} \mathrm{H}\right]$ padsevonil for 150 minutes at $37^{\circ} \mathrm{C}$. $\mathrm{B} 0$ is the binding of $\left[{ }^{3} \mathrm{H}\right]$ padsevonil in the absence of any competing compound. Data represent the mean \pm S.D. of at least three independent experiments. Data were normalized to the B0 condition and fitted using a nonlinear regression model describing competitive binding to one (straight line) or two (dotted line) binding sites. 
TABLE 4

$\mathrm{pK}_{\mathrm{i}}$ values and Hill slopes of selective synaptic vesicle protein (SV)2A ligands and diazepam for sites labeled with $\left.0.9 \mathrm{nM} \mathrm{[}{ }^{3} \mathrm{H}\right]$ padsevonil on recombinant human SV2A/B/C and on human and rat cortex at $37^{\circ} \mathrm{C}$. Data are presented as mean \pm S.D. $(n=3-10)$ and were obtained from nonlinear regression analysis of untransformed raw data using a sigmoidal dose-response model with variable slope. Missing values could not be calculated because of incomplete competition curves as a result of compound solubility limits.

\begin{tabular}{|c|c|c|c|c|c|}
\hline & Levetiracetam & Brivaracetam & UCB30889 & Padsevonil & Diazepam \\
\hline \multicolumn{6}{|l|}{$\mathrm{p} K_{i}$} \\
\hline SV2A & $5.2 \pm 0.1$ & $6.6 \pm 0.1$ & $6.7 \pm 0.2$ & $8.5 \pm 0.1$ & $<5$ \\
\hline SV2B & $3.1 \pm 0.04$ & $<4$ & $<4$ & $7.9 \pm 0.1$ & $<5$ \\
\hline SV2C & $3.2 \pm 0.1$ & $4.2 \pm 0.1$ & $4.8 \pm 0.2$ & $8.5 \pm 0.2$ & $5.6 \pm 0.1$ \\
\hline Human cortex & $5.3 \pm 0.3$ & $6.4 \pm 0.2$ & $6.7 \pm 0.2$ & $8.7 \pm 0.1$ & $5.9 \pm 0.4$ \\
\hline Rat cortex & $5.0 \pm 0.1$ & $6.4 \pm 0.1$ & $6.6 \pm 0.2$ & $8.7 \pm 0.1$ & $<5$ \\
\hline \multicolumn{6}{|l|}{ Hill slope } \\
\hline Human cortex & $-0.71 \pm 0.03$ & $-0.68 \pm 0.05$ & $-0.74 \pm 0.12$ & $-0.99 \pm 0.21$ & ND \\
\hline Rat cortex & $-0.76 \pm 0.03$ & $-0.74 \pm 0.26$ & $-0.79 \pm 0.15$ & $-0.94 \pm 0.13$ & ND \\
\hline
\end{tabular}

ND, not determined.

extremely fast kinetics: BRV's dissociation $t_{1 / 2}$ is 20 seconds at $37^{\circ} \mathrm{C}$ (Gillard et al., 2011), and that of LEV is 30 seconds at $25^{\circ} \mathrm{C}$ (Noyer et al., 1995). $\left[{ }^{3} \mathrm{H}\right] \mathrm{PSL}$ dissociation $t_{1 / 2}$ from human SV2A was 30 minutes at $37^{\circ} \mathrm{C}$. This slower off-rate was also seen in rat and human cortex, suggesting a predominance of SV2A in these tissues. The SV2A positive allosteric modulator, UCB1244283, increases both BRV and LEV binding, but by different mechanisms; an increase in the binding capacity for LEV and an increase in binding affinity and capacity for BRV (Wood and Gillard 2017). Allosteric modulation is typically associated with an increase in binding affinity; however, as a putative transporter of the major facilitator superfamily, SV2 can adopt different inward and outward facing conformations (Quistgaard et al., 2016), and with selective binding of some ligands to only one conformation, the presence of an allosteric modulator that stabilizes or induces that specific conformation could seemingly increase binding capacity. The modulator did not significantly increase $\left[{ }^{3} \mathrm{H}\right] \mathrm{PSL}$ binding but reduced its affinity for SV2A, suggesting that SV2A may exist in multiple conformational states that can be stabilized by the SV2A modulator and that the three ligands $-\left[{ }^{3} \mathrm{H}\right] \mathrm{LEV},\left[{ }^{3} \mathrm{H}\right] \mathrm{BRV}$, and $\left[{ }^{3} \mathrm{H}\right] \mathrm{PSL}-$ interact differently with it. Although LEV and BRV exert their therapeutic activity via interaction with SV2A (Matagne et al., 2008), their effect on the protein remains unknown. Therefore, it is difficult to predict the functional consequences of the slow offrate and the novel mechanism of interaction of PSL with SV2A. Given the evidence that antiseizure potency correlates with SV2A binding affinity (Noyer et al., 1995; Kaminski et al., 2008, 2009b; Gillard et al., 2011), it is plausible that such a highaffinity and long-lasting interaction could also lead to improved antiseizure efficacy.

Postsynaptically, PSL displayed low-to-moderate (micromolar) affinity for the BZD site of $\mathrm{GABA}_{\mathrm{A}} \mathrm{Rs}$ in human and rat brain membranes with no interspecies difference in potency. Results were similar in recombinant $\mathrm{GABA}_{\mathrm{A}} \mathrm{R}$ subtypes with $\alpha 1, \alpha 2$, and $\alpha 5$ subunits coexpressed with $\beta 2$ and $\gamma 2$ subunits. These subunits were chosen because they have been suggested to mediate many of the BZDs' pharmacological effects (D'Hulst et al., 2009). In functional studies, PSL lacked any direct effect on recombinant $\alpha 1 \beta 2 \gamma 2 \mathrm{GABA}_{\mathrm{A}} \mathrm{Rs}$, but it potentiated the effects of low GABA concentrations $\left(\mathrm{EC}_{20}\right.$, giving around $20 \%$ of the maximum GABA response) with a $\mathrm{pEC}_{50}$ of approximately $7.0(100 \mathrm{nM})$. This observation is in keeping with the known mechanism of action of many BZDs, positive allosteric modulators of GABA $\mathrm{Rs}$ that do not open the $\mathrm{Cl}^{-}$ channel on binding, but increase the affinity for channel gating by GABA (Sigel and Steinmann, 2012). PSL's relative efficacy compared with zolpidem was $44 \%$, indicating that it acts as a partial agonist. PSL was designed specifically to act as a partial agonist in an effort to minimize the potential for induction of tolerance. BZDs have potent antiseizure effects; however, their long-term use is limited by sedation, tolerance, and the risk of dependence (Riss et al., 2008; Rudolph and Knoflach, 2011; Ochoa and Kilgo., 2016). In epilepsy, tolerance is associated with a loss of antiseizure efficacy, a progressive increase in seizure frequency and severity, and an increased risk of withdrawal seizures, even if AEDs are kept at constant
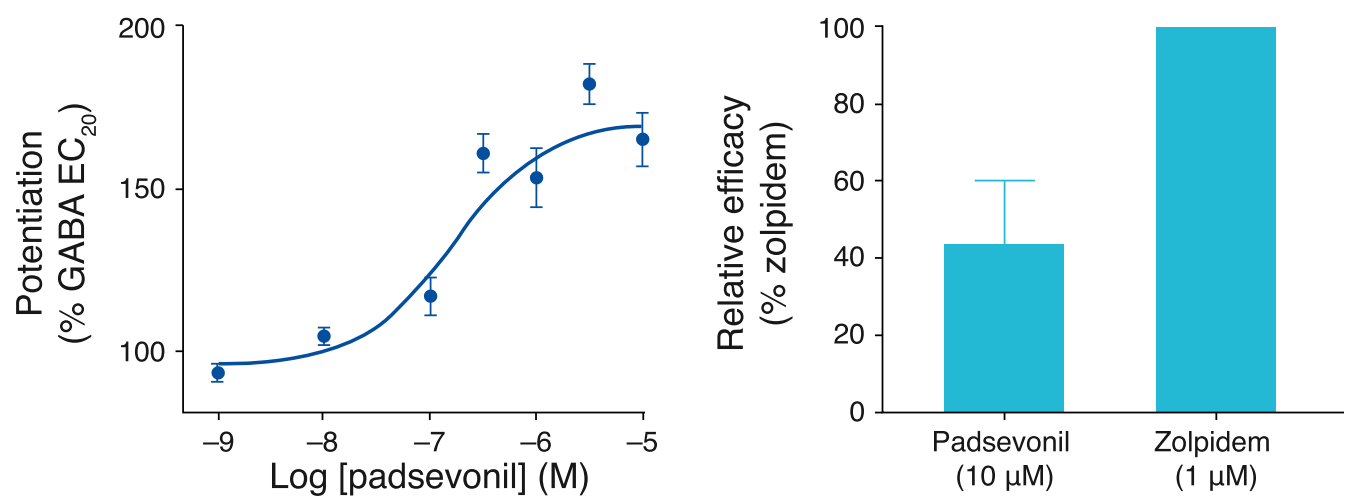

Fig. 6. Padsevonil potentiates GABA-mediated $\mathrm{Cl}^{-}$currents in $\mathrm{CHO}$ cells stably expressing human $\alpha 1 \beta 2 \gamma 2$ GABA $\mathrm{A}_{\mathrm{A}}$ receptor subunits (left panel) by acting as a partial agonist at the benzodiazepine site of the receptor (right panel; bar represents S.D.). Zolpidem, a full agonist, displays a maximal response at $1 \mu \mathrm{M}$ defined as $100 \%$. 
maintenance doses (Riss et al., 2008; Ochoa and Kilgo, 2016). Traditional BZDs such as DZP act as full agonists at the BZD site; partial agonists, however, with lower intrinsic efficacy, could potentially be associated with a lower likelihood of tolerance (Rundfeldt and Löscher, 2014). Approaches to reduce the limitations of BZDs have focused on the development of subtype-selective agents or those with low intrinsic efficacy (Rudolph and Knoflach, 2011; Rundfeldt and Löscher, 2014).

In vivo binding data indicate $50 \%$ SV2A and BZD site occupancy at 0.2 and at $36 \mathrm{mg} / \mathrm{kg}$, respectively, supporting in vitro results, with 100 -fold lower PSL potency at the BZD site compared with SV2A. In the accompanying report, PSL is shown to be active in a variety of nonclinical seizure and epilepsy models in the $0.1-10 \mathrm{mg} / \mathrm{kg}$ dose range (Leclerq et al., 2019). This finding corroborates observations that moderateto-high SV2 occupancy is associated with antiseizure activity and that low-level BZD site occupancy potentiates this effect (Kaminski et al., 2009a).

In conclusion, PSL is a first-in-class AED candidate with a presynaptic and postsynaptic mechanism of action. Studies described here have shown that PSL displays high affinity for the three SV2 isoforms, ranging from 1.5 to $6.3 \mathrm{nM}$, and low-tomoderate affinity for the $\mathrm{GABA}_{\mathrm{A}} \mathrm{R}$ BZD site, where it acts as a partial agonist, and that this profile is maintained in vivo. Furthermore, the interaction of PSL with SV2A differs from that of LEV and BRV in that it displays a markedly slower dissociation rate, and its activity is not potentiated by an SV2A modulator. These additional properties may contribute to the highly active profile of PSL in nonclinical seizure and epilepsy models, including those where the SV2A-selective ligands, LEV and BRV, show limited or no activity (Leclerq et al., 2019).

\section{Acknowledgments}

We thank John Lambert, David Urbain, Murielle Martini, and Veronique Declercq (UCB Pharma, Braine l'Alleud, Belgium) for skillful technical assistance; Barbara Pelgrims (UCB Pharma, Brussels, Belgium) for overseeing the development of the manuscript; and Azita Tofighy for providing writing support, funded by UCB Pharma.

\section{Authorship Contributions}

Participated in research design: Wood, Daniels, Wolff, Gillard.

Conducted experiments: Daniels.

Contributed new reagents or analytic tools: Provins.

Performed data analysis: Wood, Daniels, Wolff, Gillard.

Wrote or contributed to the writing of the manuscript: Wood, Wolff, Kaminski, Gillard.

\section{References}

Bajjalieh SM, Frantz GD, Weimann JM, McConnell SK, and Scheller RH (1994) Differential expression of synaptic vesicle protein 2 (SV2) isoforms. J Neurosci 14: 5223-5235

Bajjalieh SM, Peterson K, Linial M, and Scheller RH (1993) Brain contains two forms of synaptic vesicle protein 2. Proc Natl Acad Sci USA 90:2150-2154.

Bartholome O, Van den Ackerveken P, Sánchez Gil J, de la Brassinne Bonardeaux O, Leprince P, Franzen R, and Rogister B (2017) Puzzling out synaptic vesicle 2 family members functions. Front Mol Neurosci 10:148 DOI: 10.3389/fnmol.2017.00148.

Chang WP and Südhof TC (2009) SV2 renders primed synaptic vesicles competent for $\mathrm{Ca}^{2+}$-induced exocytosis. $J$ Neurosci 29:883-897.

Cheng Y and Prusoff WH (1973) Relationship between the inhibition constant (K1) and the concentration of inhibitor which causes 50 per cent inhibition (I50) of an enzymatic reaction. Biochem Pharmacol 22:3099-3108.

Crèvecoeur J, Kaminski RM, Rogister B, Foerch P, Vandenplas C, Neveux M, Mazzuferi M, Kroonen J, Poulet C, Martin D, et al. (2014) Expression pattern of synaptic vesicle protein 2 (SV2) isoforms in patients with temporal lobe epilepsy and hippocampal sclerosis. Neuropathol Appl Neurobiol 40:191-204.

Crowder KM, Gunther JM, Jones TA, Hale BD, Zhang HZ, Peterson MR, Scheller RH Chavkin C, and Bajjalieh SM (1999) Abnormal neurotransmission in mice lacking synaptic vesicle protein 2A (SV2A). Proc Natl Acad Sci USA 96:15268-15273.
Daniels V, Wood M, Leclercq K, Kaminski RM, and Gillard M (2013) Modulation of the conformational state of the SV2A protein by an allosteric mechanism as evidenced by ligand binding assays. Br J Pharmacol 169:1091-1101.

Dardou D, Dassesse D, Cuvelier L, Deprez T, De Ryck M, and Schiffmann SN (2011) Distribution of SV2C mRNA and protein expression in the mouse brain with a particular emphasis on the basal ganglia system. Brain Res 1367:130-145.

D'Hulst C, Atack JR, and Kooy RF (2009) The complexity of the GABA receptor shapes unique pharmacological profiles. Drug Discov Today 14:866-875.

Dunn AR, Hoffman CA, Stout KA, Ozawa M, Dhamsania RK, and Miller GW (2019) Immunochemical analysis of the expression of SV2C in mouse, macaque and human brain. Brain Res 1702:85-95.

Fuks B, Gillard M, Michel P, Lynch B, Vertongen P, Leprince P, Klitgaard H, and Chatelain P (2003) Localization and photoaffinity labelling of the levetiracetam binding site in rat brain and certain cell lines. Eur J Pharmacol 478:11-19.

Ghisdal P, Noel N, Pacico N, Martini M, Foerch P, Hanon E, and Wolff C (2014) Determining the relative efficacy of positive allosteric modulators of the $\mathrm{GABA}_{\mathrm{A}}$ receptor: design of a screening approach. J Biomol Screen 19:462-467.

Gillard M, Chatelain P, and Fuks B (2006) Binding characteristics of levetiracetam to synaptic vesicle protein $2 \mathrm{~A}$ (SV2A) in human brain and in CHO cells expressing the human recombinant protein. Eur J Pharmacol 536:102-108.

Gillard M, Fuks B, Leclercq K, and Matagne A (2011) Binding characteristics of brivaracetam, a selective, high affinity SV2A ligand in rat, mouse and human brain: relationship to anti-convulsant properties. Eur J Pharmacol 664:36-44.

Gillard M, Fuks B, Michel P, Vertongen P, Massingham R, and Chatelain P (2003) Binding characteristics of $[3 \mathrm{H}] \mathrm{ucb} 30889$ to levetiracetam binding sites in rat brain. Eur J Pharmacol 478:1-9.

Gravielle MC (2016) Activation-induced regulation of $\mathrm{GABA}_{\mathrm{A}}$ receptors: is there a link with the molecular basis of benzodiazepine tolerance? Pharmacol Res 109: 92-100.

Janz R, Goda Y, Geppert M, Missler M, and Südhof TC (1999a) SV2A and SV2B function as redundant $\mathrm{Ca} 2+$ regulators in neurotransmitter release. Neuron 24: 1003-1016.

Janz R and Südhof TC (1999b) SV2C is a synaptic vesicle protein with an unusually restricted localization: anatomy of a synaptic vesicle protein family. Neuroscience 94:1279-1290.

Kaminski RM, Gillard M, Leclercq K, Hanon E, Lorent G, Dassesse D, Matagne A and Klitgaard H (2009b) Proepileptic phenotype of SV2A-deficient mice is associated with reduced anticonvulsant efficacy of levetiracetam. Epilepsia 50:1729-1740.

Kaminski RM, Matagne A, Leclercq K, Gillard M, Michel P, Kenda B, Talaga P, and Klitgaard $\mathrm{H}$ (2008) SV2A protein is a broad-spectrum anticonvulsant target: functional correlation between protein binding and seizure protection in models of both partial and generalized epilepsy. Neuropharmacology 54:715-720.

Kaminski RM, Matagne A, Patsalos PN, and Klitgaard H (2009a) Benefit of combination therapy in epilepsy: a review of the preclinical evidence with levetiracetam. Epilepsia 50:387-397.

Klitgaard H, Matagne A, Nicolas J-M, Gillard M, Lamberty Y, De Ryck M, Kaminski RM, Leclercq K, Niespodziany I, Wolff C, et al. (2016) Brivaracetam: rationale for discovery and preclinical profile of a selective SV2A ligand for epilepsy treatment. Epilepsia 57:538-548.

Leclerq K, Matagne A, Provins L, Klitgaard H, and Kaminski RM (2019) Pharmacological profile of the antiepileptic drug candidate padsevonil-characterization in rodent seizure and epilepsy models. J Pharmacol Exp Ther.

Li J, Fish RL, Cook SM, Tattersall FD, and Atack JR (2006) Comparison of in vivo and ex vivo $[3 \mathrm{H}]$ flumazenil binding assays to determine occupancy at the benzodiazepine binding site of rat brain $\mathrm{GABA}_{\mathrm{A}}$ receptors. Neuropharmacology $\mathbf{5 1}$ 168-172.

Löscher W, Gillard M, Sands ZA, Kaminski RM, and Klitgaard H (2016) Synaptic vesicle glycoprotein $2 \mathrm{~A}$ ligands in the treatment of epilepsy and beyond. CNS Drugs 30:1055-1077.

Lynch BA, Lambeng N, Nocka K, Kensel-Hammes P, Bajjalieh SM, Matagne A, and Fuks B (2004) The synaptic vesicle protein SV2A is the binding site for the antiepileptic drug levetiracetam. Proc Natl Acad Sci USA 101:9861-9866.

Matagne A, Margineanu DG, Kenda B, Michel P, and Klitgaard H (2008) Anticonvulsive and anti-epileptic properties of brivaracetam (ucb 34714), a high-affinity ligand for the synaptic vesicle protein, SV2A. Br J Pharmacol 154:1662-1671.

Meehan AL, Yang X, McAdams BD, Yuan L, and Rothman SM (2011) A new mechanism for antiepileptic drug action: vesicular entry may mediate the effects of levetiracetam. J Neurophysiol 106:1227-1239.

Meehan AL, Yang X, Yuan LL, and Rothman SM (2012) Levetiracetam has an activity-dependent effect on inhibitory transmission. Epilepsia 53:469-476.

Mendoza-Torreblanca JG, Vanoye-Carlo A, Phillips-Farfán BV, Carmona-Aparicio L, and Gómez-Lira G (2013) Synaptic vesicle protein 2A: basic facts and role in synaptic function. Eur $J$ Neurosci 38:3529-3539.

Molinoff PB, Wolfe BB, and Weiland GA (1981) Quantitative analysis of drugreceptor interactions: II. Determination of the properties of receptor subtypes. Life Sci 29:427-443.

Noyer M, Gillard M, Matagne A, Hénichart JP, and Wülfert E (1995) The novel antiepileptic drug levetiracetam (ucb L059) appears to act via a specific binding site in CNS membranes. Eur J Pharmacol 286:137-146.

Ochoa JG and Kilgo WA (2016) The role of benzodiazepines in the treatment of epilepsy. Curr Treat Options Neurol 18:18 DOI: 10.1007/s11940-016-0401-x.

Ohno Y and Tokudome K (2017) Therapeutic role of synaptic vesicle glycoprotein 2A (SV2A) in modulating epileptogenesis. CNS Neurol Disord Drug Targets 16: $463-471$.

Quistgaard EM, Löw C, Guettou F, and Nordlund P (2016) Understanding transport by the major facilitator superfamily (MFS): structures pave the way. Nat Rev Mol Cell Biol 17:123-132.

Riss J, Cloyd J, Gates J, and Collins S (2008) Benzodiazepines in epilepsy: pharmacology and pharmacokinetics. Acta Neurol Scand 118:69-86.

Rudolph U and Knoflach F (2011) Beyond classical benzodiazepines: novel therapeutic potential of GABAA receptor subtypes. Nat Rev Drug Discov 10:685-697. 
Rundfeldt C and Löscher W (2014) The pharmacology of imepitoin: the first partial benzodiazepine receptor agonist developed for the treatment of epilepsy. CNS Drugs 28:29-43.

Sigel E and Steinmann ME (2012) Structure, function, and modulation of GABA(A) receptors. J Biol Chem 287:40224-40231.

Tokudome K, Okumura T, Shimizu S, Mashimo T, Takizawa A, Serikawa T, Terada R, Ishihara S, Kunisawa N, Sasa M, et al. (2016) Synaptic vesicle glycoprotein 2A (SV2A) regulates kindling epileptogenesis via GABAergic neurotransmission. Sci Rep 6:27420, doi: 10.1038/srep27420 27265781.

Tokudome K, Okumura T, Terada R, Shimizu S, Kunisawa N, Mashimo T, Serikawa T, Sasa M, and Ohno Y (2016) A Missense Mutation of the Gene Encoding Synaptic Vesicle Glycoprotein 2A (SV2A) Confers Seizure Susceptibility by Disrupting Amygdalar Synaptic GABA Release. Front Pharmacol 7:210, doi: 10.3389/ fphar.2016.00210 27471467.

Venkatesan K, Alix P, Marquet A, Doupagne M, Niespodziany I, Rogister B, and Seutin V (2012) Altered balance between excitatory and inhibitory inputs onto
CA1 pyramidal neurons from SV2A-deficient but not SV2B-deficient mice. $J$ Neurosci Res 90:2317-2327.

Vinkers CH and Olivier B (2012) Mechanisms underlying tolerance after long-term benzodiazepine use: a future for subtype-selective GABA(A) receptor modulators? Adv Pharmacol Sci 2012:416864 DOI: 10.1155/2012/416864.

Wood MD and Gillard M (2017) Evidence for a differential interaction of brivaracetam and levetiracetam with the synaptic vesicle $2 \mathrm{~A}$ protein. Epilepsia 58:255-262.

Yang X, Bognar J Jr, He T, Mohammed M, Niespodziany I, Wolff C, Esguerra M, Rothman SM, and Dubinsky JM (2015) Brivaracetam augments short-term depression and slows vesicle recycling. Epilepsia 56:1899-1909.

Address correspondence to: Michel Gillard, UCB Pharma, Neurosciences Therapeutic Area, Chemin du Foriest, 1420 Braine l'Alleud, Belgium. E-mail: michel.gillard@ucb.com 